\title{
O ROMPER COM SILÊNCIO: CÍRCULOS DE CULTURA DE CONTAÇÃO DE HISTÓRIAS EM UMA ASSOCIAÇÃO DE IDOSOS
}

\author{
BREAKING DOWN THE SILENCE: CULTURE CIRCLES OF STORYTELLING IN AN \\ ELDERLY CARE HOME
}

\section{EL ROMPER CON SILENCIO: CÍRCULOS DE CULTURA DE CUENTACUENTOS EN UNA ASOCIACIÓN DE ADULTOS MAYORES}

Joana Dark Leite*

Marcio Penna Corte Real ${ }^{*}$

\begin{abstract}
Resumo: O silenciamento tem privado os anciãos de intercambiar suas experiências. Percebemos que há um silenciamento dos conhecimentos fundantes dos idosos. Esse silenciamento tem como consequência o não contar, o não narrar suas experiências. Por isso, temos vivido um processo de contações de histórias, análise, debates e vivências no círculo de cultura de contação de histórias, proporcionando um momento de reflexão aos idosos. Para que se re-encontrem como criadores de cultura e também com suas experiências fundantes. Os momentos de círculo de cultura de contação de histórias, têm se desenvolvido e se transformando em aprendizado e redescoberta. A história geradora impulsiona outras histórias, conhecimentos e vivencias. A participação no círculo de cultura de contação de história tem se efetivado em possibilidades de re-descoberta da arte da narração de histórias, interação com a história e a vivência do outro. Assim, percebemos que ao reconstruir a sua palavra, reconstrói-se também o mundo de narrador. Estamos vivenciando, um caminho com os idosos no qual o ato de fiar e tecer histórias têm levado os idosos a se reconhecerem como contadores de histórias e romper com a cultura do silêncio provocada pela opressão social.
\end{abstract}

Palavras-chave: Silenciamento. Círculo de Cultura. Contação de Histórias. Idosos.

\begin{abstract}
Silencing has deprived the elders of exchanging their experiences. We realize that there is a silencing of the foundational knowledge of the elderly. This silencing has the consequence of not telling, not telling their experiences. Therefore, we have lived a process of storytelling, analysis, debates and experiences in the culture circle of storytelling, providing a moment of reflection for the elderly, so that they refind themselves as creators of culture. The moments of storytelling culture circle have developed and transformed into learning and rediscovery. The story created propels other stories, knowledge and experiences. Participation in the culture circle of storytelling has been effected in possibilities of rediscovering the art of storytelling, interacting with the story and the experience of the other. Thus, we realize that in rebuilding their word, the world of the narrator is also rebuilt. We are living a path with the elderly in which the act of creating and weaving stories has led the elderly to recognize themselves as storytellers and to break with the culture of silence brought about by social oppression.
\end{abstract}

Keywords: Silencing. Culture circle. Storytelling. Elderly.

\footnotetext{
* Mestranda em Performances Culturais pelo Programa de Pós-Graduação Interdisciplinar em Performances Culturais - Mestrado (PPGIPC). E-mail: joanadarkl@yahoo.com.br

** Doutor em Educação pela Universidade Federal de Santa Catarina. Professor da Faculdade de Educação da Universidade Federal de Goiás. Professor do Programa de Pós-Graduação em Performances Culturais - Interdisciplinar, EMAC/UFG. E-mail: mpcortereal@yahoo.com,br
} 
Resumen: El silenciamiento ha privado a los adultos mayores de intercambiar sus experiencias. Nos damos cuenta de que hay un silenciamiento de los conocimientos fundamentales de las personas mayores. Este silenciamiento tiene como consecuencia el no contar, el no narrar sus experiencias. Por eso, hemos vivenciado un proceso de narración de cuentos, análisis, debates y vivencias en el círculo de cultura de cuentacuentos, proporcionando un momento de reflexión para los mayores, con el fin de reencontrarse como creadores de cultura y con sus experiencias fundacionales. Los momentos de círculo de cultura de cuentacuentos, se han desarrollado y convertido en aprendizaje y redescubrimiento. La historia generadora impulsa otras historias, conocimientos y vivencias. La participación en el círculo de cultura de narración de historias ha hecho efectivas posibilidades de redescubrimiento del arte de la narración, la interacción con la historia y con la vivencia del otro. Así pues, vemos que al reconstruir su palabra, se reconstruye también el mundo del narrador. Vivimos un camino con los adultos mayores en la que el acto de hilar y tejer historias los ha llevado a reconocerse como contadores de historias y romper con la cultura del silencio causada por la opresión social.

Palabras clave: Silenciamento. Círculo de cultura. Cuentacuentos. Adultos mayores.

\section{Introdução}

Este texto é uma reflexão sobre as possibilidades de ressignificação das experiências fundantes ${ }^{1}$, por meio do círculo de cultura de contação de histórias em uma Associação de idosos $^{2}$.

\footnotetext{
${ }^{1}$ As experiências fundantes são refletidas como forma de "respeitar a leitura de mundo do educando significa tomá-la como ponto de partida para a compreensão do papel da curiosidade, de modo geral, e da humana, de modo especial, como um dos impulsos fundantes da produção do conhecimento. É preciso que, ao respeitar a leitura do mundo do educando para ir mais além dela, o educador deixe claro que a curiosidade fundamental à inteligibilidade do mundo é histórica e se dá na história, se aperfeiçoa, muda qualitativamente, se faz metodicamente rigorosa. E a curiosidade assim metodicamente rigorizada faz achados cada vez mais exatos. No fundo, o educador que respeita a leitura de mundo do educando, reconhece a historicidade do saber, o caráter histórico da curiosidade, desta forma, recusando a arrogância cientificista, assume a humildade crítica, própria da posição verdadeiramente científica" (FREIRE, 1996, p.46).

${ }^{2}$ Assim, o espaço desta investigação-ação consiste em
uma Associação de idosos, localizada na cidade de
Goiânia/GO, que, há 28 anos, realiza atividades recre-
ativas e formativas para idosos. Possibilita um ambien-
te na forma ponto de encontro de pessoas, que têm à
sua disposição diversas atividades. As atividades são
previamente planejadas pela diretoria e fixadas em um
mural. Além da escolha de uma atividade a ser realiza-
}

O processo de ação reflexão no círculo de cultura tem nos mostrado que há um silenciamento das vivências dos idosos. Esse silenciamento é opressor, pois a sociedade ao retirar o idoso do círculo produtivo, retira também o envolvimento com o outro. Por não se envolver com os outros e com a sociedade, o idoso é silenciado. Automaticamente, muitos deixam de contar suas histórias, justamente por perceberem que essas não tem valor algum. Ou seja, o ancião deixa de ser um contador de histórias.

Dessa forma, os momentos que temos desenvolvido no círculo de cultura de contação de histórias apontam que a prática investigativa no círculo de cultura tem problematizado esse silenciamento. Os idosos têm redescoberto a sua posição de criadores de cultura. Assim, a partir da dinamização do círculo de cultura, temos reencontrado contadores de histórias na Associação de idosos, e consideramos que ao reencontrar

da em conjunto, os participantes também realizam na associação refeições, como café da manhã, almoço e lanche. Nas programações, encontram-se alternativas para a sua escolha, típicas do Estado de Goiás, como folia, pamonhada, festa junina, bailes, ateliê de fiandeiras, de tapetes. E, hoje em dia a contação de histórias que faz parte da programação mensal. 
os contadores de história estamos também reencontrando vozes e intercambiando experiências. Por isso, convidamos você, leitor, a embarcar nessa história reflexiva sobre o círculo de cultura de contação de histórias, sobre a prática investigativa do círculo de cultura, os contadores de história da associação e refletir sobre as nossas considerações sobre esses momentos.

\section{A prática investigativa do círculo de cultura}

Percebemos que há um silenciamento dos conhecimentos fundantes dos idosos que tem como consequência o não contar, o não narrar suas experiências. Ou seja, ao contar uma história por meio dos seus conhecimentos fundantes, os anciãos estão intercambiando experiências. Porém, o que temos refletido a partir de Benjamin (2011), é que

o narrador - por mais familiar que nos soe esse nome - não está absolutamente presente entre nós, em sua eficácia viva... é a experiência da arte de narrar que está em vias de extinção... é como se estivéssemos sendo privados de uma faculdade que nos parecia totalmente segura e inalienável: a faculdade de intercambiar experiências (p.213)

O silenciamento tem privado os anciãos de intercambiar suas experiências. Por isso, temos vivido um processo de análise, debates e vivências no círculo de cultura de contação de histórias, para os idosos perceberem que são criadores de cultura e também que suas experiências fundantes sejam relembradas, ressignificadas e contadas. A falta de reconhecimento de suas histórias provoca um estado anestésico do não dizer.

Os idosos trazem consigo diversos conhecimentos, histórias, memórias e vivências que muitas vezes ficam adormecidos. Existem múltiplas formas de opressão sofridas por eles, sendo que uma delas é a de, por vezes, não poderem falar, contar e compartilhar suas experiências. Talvez, inclusive fruto da forma como vivemos em sociedade e do papel que nesta ocupa o idoso - o que tem deixado de ocupar, Chauí aponta que,

a função social do velho é lembrar e aconselhar - memini, moneo - unir o começo e o fim, ligando o que foi e o porvir. Mas a sociedade capitalista impede a lembrança, usa o braço servil do velho e recusa seus conselhos. Sociedade que, diria Espinosa, "não merece o nome de Cidade, mas o de servidão e barbárie”, a sociedade capitalista desarma o velho mobilizando mecanismos pelos quais oprime a velhice, destrói os apoios da memória e substitui a lembrança pela história oficial celebrativa (CHAUÍ apud BOSI, 2004).

Essa reflexão tem contribuído para que nós nos reencontremos uns com os outros, com nossas histórias, experiências, vivências e leituras de mundo. Os idosos da Associação têm se reencontrado consigo, assim como a educadora-educanda-contadora de história também tem reencontrado a cada círculo de cultura de contação de histórias uma forma de contar histórias3. Justamente porque o círculo de cultura é onde "encontram-se e reencontram-se todos no mesmo mundo comum e, da coincidência das intenções que o objetivam,

\footnotetext{
${ }^{3}$ Antes de cada círculo de cultura de contação de histórias há um planejamento de que histórias, causos, vivências que será contado. Por isso, se faz necessário uma pesquisa, análise e leituras de autores regionais que contaram na forma escrita histórias especificas da região, como: Cora Coralina, José J. Veiga. Bariane Oretencio, Bernardo Élis, Carmo Bernardes, Graciliano Ramos, Camara Cascudo, Diane Valdez, Rolando Boldrin. Ou ouvir, contadores de causo como: Geraldinho Nogueira, de Bela Vista de Goiás seus causos ficaram famosos no programa frutos da Terra e muitos estão disponíveis no You tube.
} 
exsurge a comunicação, o diálogo que criticiza e promove os participantes do círculo" (FIORI, 1987, p.6).

A participação no círculo de cultura de contação de história tem se efetivado em possibilidades de redescoberta da arte da narração de histórias, interação com a história e a vivência do outro. Dessa forma, qual o ponto de partida do círculo de cultura de contação de histórias? "O ponto de partida para o trabalho no círculo de cultura está em assumir a liberdade e a crítica como o modo de ser do homem" (Weffort, 1967, p.14, in Educação como prática da liberdade). Por isso, tem sido um grande desafio contribuir para que os idosos sejam mais ${ }^{4}$, para que alcancem a liberdade de poder contar histórias e de poder ser.

Trabalhamos com o círculo de cultura de contação de histórias justamente porque

o círculo se constitui assim em um grupo de trabalho e de debate. Seu interesse central é o debate da linguagem no contexto de uma prática social livre e crítica. Liberdade e crítica que não podem se limitar às relações internas do grupo mas que necessariamente se apresentam na tomada de consciência que este realiza de sua situação social. Deste modo, cabe ao coordenador apresentar, antes de dar início à alfabetização, algumas imagens (sem palavras) que propiciem o debate sobre as noções de cultura

\footnotetext{
${ }^{4}$ Os idosos em sua maioria são considerados um ser menos, justamente por causa da opressão social. Por isso, no círculo de cultura de contação de histórias trabalhamos com a ideia de ser mais, com aponta Freire (1994): “A situação de opressão em que se "formam”, em que "realizam" sua existência, os constitui nesta dualidade, na qual se encontram proibidos de ser. Basta, porém, que homens estejam sendo proibidos de ser mais para que a situação objetiva em que tal proibição se verifica seja, em si mesma, uma violência. Violência real, não importa que, muitas vezes, adocicada pela falsa generosidade a que nos referimos, porque fere a ontológica e histórica vocação dos homens - a do ser mais “(p.23).
}

e de trabalho. (WEFFORT apud FREIRE, 1994).

Exatamente por isso, momentos de contação de histórias se fazem presentes no círculo de cultura, para que idoso-educando-educador ouça e em seguida se sinta convidado a contar também uma história. $\mathrm{O}$ ato de contar uma história desenvolve momentos onde os idosos podem narrar os seus valores históricos, culturais e sociais, ou seja, "integrando ao seu contexto, resultante de estar não apenas nele, mas com ele” (FREIRE, 1996, p.50).

As histórias contadas pela educadora-educanda-contadora de histórias são “as imagens que propiciem o debate sobre as noções de cultura e de trabalho” (WEFFORT, 1967, p.14), que realiza a função de coordenador do debate como menciona Freire (1967). As histórias contadas são os temas geradores de outras histórias, a partir de uma história, que sempre é em torno de uma vivência dos causos populares, da literatura regional, ou da própria vivência. O diálogo se abre e o grupo participante poderá contar a sua história, pois quem "dialoga, dialoga com alguém sobre alguma coisa” (FREIRE, 1996, p.116).

No círculo de cultura de contação de histórias “essa alguma coisa” mencionada por Freire (1996) são as histórias contadas que, além dinamizar o diálogo, os idosos vivem momentos reflexivos sobre seus conhecimentos e práticas culturais. Assim, “o círculo de cultura é o lugar onde trava a relação do ser humano mediado pelas suas relações "homens-mundo" (FREIRE, 1996).

Na relação do diálogo sobre práticas culturais, histórias e memórias teremos a construção de uma narrativa. Deste modo, essas narrativas carregam em seu bojo os valores sociais de determinada sociedade onde homens e mulheres tornam-se atores no "drama 
social” (TURNER apud HARTMANN, 2000, pg. 107)

Portanto, dirigimos nossa atenção para os “atores do drama social”, na medida em que temos procurado investigar e compartilhar as memórias e experiências do grupo de narradores-idosos nos círculos de cultura de contação de histórias. A partir desse entendimento, a investigação tem procurado problematizar a contação de histórias como possibilidade de ressignificar as leituras de mundo nos idosos ao mesmo tempo que procuramos pensar sobre o seu lugar na sociedade" 5 .

Preliminarmente, podemos verificar que, embora no início do trabalho, as participações dos idosos fossem tímidas, ao longo do seu desenvolvimento e do estabelecimento de uma relação de maior reciprocidade, as participações tornaram-se mais intensas, permitindo pensar e agir juntos sobre até que ponto conseguimos ampliar e quem sabe ressignificar nossas leituras em comum sobre o mundo que nos desafia.

\section{Os contadores de história da Associação de Idosos}

Os momentos de círculo de cultura de contação de histórias têm se desenvolvido e se transformando em aprendizado e redescoberta. A história geradora impulsiona outras histórias, conhecimentos e vivências, pois, conforme Freire (1967) "uma palavra geradora tanto pode englobar a situação toda, quanto pode referir-se a um dos elementos da situação". Ao apresentar dois contadores de histórias chamamos a atenção para o fato

\footnotetext{
${ }^{5}$ Parte do texto apresentado no EDIPE (Encontro Nacional de Didática e Prática de Ensino): CORTE REAL; PEREIRA; LEITE. Investigaçõ-ação das performances culturais: o método expositivo como problematização da formação de educadores, Goiânia, 2015.
}

de que esses se redescobriram contadores de histórias.

Apresentaremos momentos dos círculos de cultura de contação de histórias, onde eles foram se envolvendo com a sua própria história enfrentando o silenciamento que a sociedade provoca nos idosos. Os contadores de histórias da Associação redescobriram a importância da sua luta enquanto pessoa, reconhecendo a real significação que cada um tem para a sociedade. Freire (1987) diz sobre a significação profunda essa descoberta:

descobrirem-se, portanto, através de uma modalidade de ação cultural, dialógica, problematizadora de si mesmos em seu enfrentamento com o mundo, significa, num primeiro momento, que se descubram como Pedro, Antônio, com Josefa, com toda a significação profunda que tem esta descoberta. No fundo, ela implica numa percepção distinta da significação dos signos. Mundo, homens, cultura, árvore, trabalho, animal, vão assumindo a significação verdadeira que não tinham. (FREIRE, 1987, p.101)

Assim, percebemos que ao reconstruir a palavra, reconstrói-se também o mundo de narrador. O senhor Valdivino, aos 75 anos de idade, nos mostrou que o círculo de cultura de contação de histórias o desafiou a revisitar suas memórias e ele se tornou um contador de causos. Sua participação assumiu a significação de contar histórias, de relembrar momentos de sua infância, juventude e de adulto-idoso; seu Valdivino afirma que:

"com a experiêcia de vida que tenho, esse momento de contação de histórias é muito importante eu tenho certeza".

Ao relembrar suas memórias, perceber que pode contar suas experiências; descobre também que é testemunha da sua própria história, como aponta Fiori citado por Freire 
pensar o mundo é julgá-lo; e a experiência dos círculos de cultura mostra que o alfabetizando, ao começar a escrever livremente, não copia palavras, mas expressa juízos. Estes, de certa maneira, tentam reproduzir o movimento de srta própria experiência; o alfabetizando, ao dar-lhes forma escrita, vai assumindo, gradualmente, a consciência de testemunha de uma história de que se sabe autor. Na medida em que se apercebe como testemunha de sua história, sua consciência se faz reflexivamente mais responsável dessa história (FREIRE, 1987).

A partir dos temas outras histórias surgem por meio da contação. Assim, verificamos que o ato de contar da educadora-educanda contadora de histórias gera outras histórias. Ao ouvir as histórias contadas, imagens surgem e instigam o universo interno dos participantes. Ao ouvir um narrador-idoso outro também se dispõe a contar; o senhor Valdivino afirmou:

"Joaninha", é tocando o assunto que a gente vai recordando" (Diário de Campo, 2015).

Dessa forma, o círculo de cultura de contação de histórias tem acontecido e mostrado que "a arte de narrar é uma relação alma, olho e mão: assim transforma o narrador sua matéria, a vida humana” (BOSI, 2004, p.90). Após a contação de histórias, os temas geradores que a história propunha são discutidos, conforme mostra a figura 1 :

\footnotetext{
${ }^{6}$ Joaninha é a forma como os educandos-educadores chamam à educadora-educanda-contadora de histórias Joana Dark.
}

Figura 1, 2015: Círculo de cultura de contação de histórias na Associação de Idosos do Brasil.

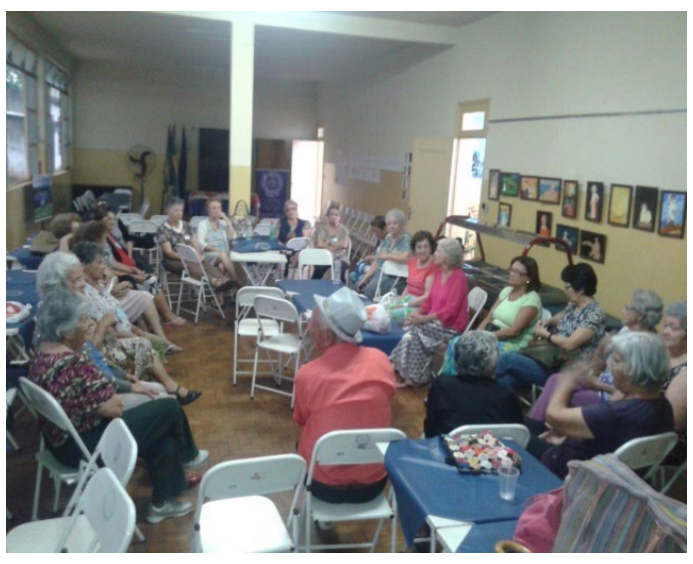

O senhor Valdivino (sentado de costas) realiza várias intervenções que foram desenvolvidas por meio do círculo de cultura de contação de histórias. Afirma que:
"contar uma história é encontrar com o outro... Sou uma pessoa muito simples, mas agora eu sou assim: eu já contei duas his- tórias - de uma foi passando para outra, porque a cada palavra que o companhei- ro diz, eu lembro um causo" (Diário de Campo, 2015).

Nesse dia foi interessante de observar que "cada memória individual é um ponto de vista sobre a memória coletiva” (BOSI, 2011, p.413). A partir da história contada pela educadora-educanda-contadora de histórias sobre a fogueira de são João, na fazenda da avó Dita, histórias surgiram da história. Após, a fogueira queimar o avô Mino guardava toda a cinza. Porque a cinza estava benta. A cinza servia para colocar nos sacos de feijão para não dar bichos (carunchos). O senhor Valdivino confirmou a história e contou que: “também usava tirar o sapato quando a fogueira estava com a brasa quase acabando e passar o pé em cima da brasa. Quem tinha fé o pé não queimava. Agora quem não tinha o pé 
queimava todinho”. Outra senhora confirmou a história e disse que várias vezes quando era jovem fez “essa travessura de fé”.

O senhor Valdivino contou que:

"Esse negocio de tirar o sapato para passar na fogueira, eu lembrei de uma história verdadeira. Eu tinha um tio que usou a mesma bota por mais de 70 anos. Não precisa espantar, naquele tempo o sapato era só para sair...as pessoas não saiam muito e ficavam muito descalço. Não era como hoje em dia. Hoje em dia para vir aqui tem um sapato, para ir na igreja outro sapato, para ir passear outro. Dizem que tem pessoas que guardam em um lugar especifico o sapato. Que coisa heim! Coitado do meu tio teve só uma bota". Uma senhora disse: "quando eu era criança eu vivia descalço. O meu primeiro sapato eu só tive aos 14 anos, assim mesmo foi presenteado por uma pessoa de fora. O que o senhor Valdivino esta contando é uma verdade em partes. Senhor Valdivino o seu tio usou a mesma botinha por 70 anos? Eu não sei não heim! (Todos riram muito)" (Diário de campo, 2015).

A memória individual do senhor Valdivino confirmou a memória coletiva de muitos que ali estavam e vivenciaram passar pela fogueira no dia de São João. As histórias contadas de seu Valdivino traziam consigo uma análise dos acontecimentos, do tempo e das dificuldades. A história do seu tio em ter apenas uma bota para sair é uma análise de como era difícil para algumas pessoas adquirir coisas, ou seja, “contar já é refletir sobre os acontecimentos narrados” (RICOUER apud HARTMANN, 2011, p. 65).

Nesse dia contamos histórias por mais de uma hora no círculo e ao conta-la por meio deste trabalho verificamos o que Bosi (2011) disse: "o indivíduo é o memorizador e das camadas do passado a que tem acesso pode reter objetos que são, para ele, e só para ele, significativos dentro de um tesouro comum”.

Ao vivenciarmos esse dia de círculo de cultura descobrimos vários tesouros comuns de histórias e vivências. O senhor Valdivino participou ativamente sempre muito empenhado e mostrou sempre com muito entusiasmo a alegria de poder contar uma história. A sua satisfação com a redescoberta fez com que outros idosos quisessem participar do círculo de cultura de contação de histórias. No dia agendado para a contação de histórias, o senhor Valdivino era sempre o primeiro a chegar e ficava ansioso dizendo:

"hoje eu vou contar muita verdade, porque vocês sabem: eu só abro a boca quando tenho certeza” (Diário de Campo, 2015).

Também participava ativamente do grupo de fiandeiras tocando viola e cantando para que as fiandeiras da Associação produzissem ao som de belas modas de viola. Sua frase ficou famosa no meio de todos "eu só conto aquilo que é verdade”, uma forma divertida de brincar com as histórias fictícias misturadas com a realidade.

Em novembro de 2015 o senhor Valdivino faleceu por causa de um câncer. Todos lembram com muito carinho a sua forma alegre de contar uma história. Também de como interagia com todos sempre colocando muito sentido em tudo que o companheiro estava contando. Ao contar essa história percebemos que o senhor Valdivino apontou caminhos, nos mostrado o quanto é libertador a redescoberta do ato de contar na velhice, o quanto é importante o reconhecimento dos conhecimentos que muitas vezes estão adormecidos. O senhor Valdivino nos ensinou que: "o narrador está presente ao lado do ouvinte. Suas mãos, experimentadas no trabalho, fazem gestos que sustentam a história, que dão asas aos fatos principiados pela sua voz. 
Tira segredos e lições que estavam dentro das coisas” (BOSI, 2011, p.90).

Estamos vivenciando um caminho com os idosos no qual o ato de fiar e tecer histórias os têm levado a se reconhecerem como contadores de histórias. Percebemos que os idosos estão identificando "que a própria vida social se constitui no ato de contar histórias" (BAUMAN apud HARTMAN, 2011, p. 61).

No início do círculo, uma educanda-educadora apenas ouvia atentamente, divertia-se e prestava muita atenção. A partir de alguns momentos a educanda-educadora Maria Lacerda de 67 anos, começou a contar suas histórias. Ou seja, a sua experiência passou a fazer sentido. Hartmann (2011) diz que "uma das principais maneiras que o ser humano teria de manifestar, comunicar e até mesmo compreender a experiência seria colocá-la em forma de narrativa”. A sua experiência da infância, histórias ouvidas na juventude e sua vivencia passou a ser ressignificada e contada. Maria Lacerda nos contou que ouviu a seguinte história:

"era um grupo de pessoas doidas. Eles foram levados para passear, as pessoas que cuidavam queriam ver quem era mais doido. Pediu para subir em um pé de manga e ver se tinha manga madura. Um subiu... perguntaram para ele: está madura? Está! E caia no chão. Assim aconteceu com todos. Até que chegou um e disse: não está é podre por isso, que vai cair. Ou seja, todos estavam praticamente no mesmo nível não tinha nenhum são" (Diário de Campo, 2015).

Nos chama atenção, que para Maria Lacerda o ato de contar histórias foi um processo de ressignificação de suas experiências, de suas leituras de mundo e de suas vivências. Ou seja, "toda experiência é exclusivamente pessoal, individual, única e nunca poderá ser totalmente partilhada. A chave para tentar transcender essa limitação seria interpretar as expressões da experiência (performances, objetificações, narrativas, textos...) que darão forma e significado às experiências” (BRUNER apud HARTMANN, 2011, p. 229).

Essas expressões da experiência são construídas nas memórias, contos, festas, cerâmicas, ritos, dramas, imagens (GEERTZ apud HARTMANN, 2011, p. 231). A Maria Lacerda nos apresenta por meio de suas expressões que "todo ato de performance é reflexivo, cria uma experiência ao mesmo tempo reflete sobre ela (HARTMANN, 2011, p. 231). Ao interpretar as expressões da experiência que são construídas também na memória, a educanda-educadora Maria Lacerda traz a reflexão de que, para contar uma história, é preciso se posicionar frente a quem está ouvindo. Ao experenciar esse ato, o seu comportamento é restaurado. Ao contar uma história Maria Lacerda se posicionou de pé, adquiriu uma postura ereta, procurando mexer com as mãos e projetando sua voz. Ao terminar a história sentou-se e retornou a postura normal sendo agora, ela mesma. Schechner (2006) diz que

comportamento restaurado é o processo principal de todos os tipos de performance, seja na vida cotidiana, na cura, nos ritos, em ações, e nas artes (...) está "lá fora”, à parte do "eu”. Colocando em palavras próprias, o comportamento restaurado "sou eu me comportando como se fosse outra pessoa", ou "como me foi dito para fazer", ou "como aprendi" (p. 34).

Ao contar uma história no círculo de cultura de contação na Associação de Idosos, Maria Lacerda passa a desenvolver uma performance da experiência. Na contação de histórias realizada na creche no ano anterior (2014) ficou sentada ouvindo a educadora-educanda-contadora de histórias contar. No ano de 2015 contou histórias e cantou cantigas 
para as crianças. Observamos que suas palavras são próprias e usadas por meio das histórias e cantigas. Ou seja, há um comportamento restaurado de contadora de histórias frente às crianças e companheiros da Associação.

Assim, desenvolve seu eu de contadora de histórias da forma como apreendeu, observou ao longo da vida e no círculo de cultura. Realiza o seu momento de contação da forma como ela mesma acredita que é possível realizar para contar uma história.

Os idosos no círculo de cultura de contação de história a cada encontro estão revivendo o tempo, alinhando seus corpos e contando histórias por meio de suas performances da experiência ${ }^{7}$ e por meio de suas representações cotidianas, pois "performances marcam identidades, dobram o tempo, remodulam e adornam o corpo, e contam estórias” (SCHECHNNER, 2006, p.29).

Narradores idosos da associação têm fiado e tecido enquanto ouvem histórias. O ato de fiar a história no círculo de cultura de contação de histórias têm se convertido em tecitura da história vivenciada, que ao contar se transforma em aprendizado. Essas histórias têm retornado como forma de aprendizado e ressignificado as práticas culturais desses

\footnotetext{
7 "Performance é um tipo de comportamento, uma abordagem da experiência; é jogo, esporte, estética, entretenimento popular, teatro experimental, entre outras coisas”(SHECHNER apud HARTMANN, 2011, p.235). Por isso, adotamos o termo Performances da experiência, justamente porque como Hartmann(2011) diz a partir de Sulivan(1986) "a performance é uma forma hermenêutico pois tem como principal constituinte de sua ação a reflexividade...Para o autor, todas essas teorias são tentativas de delinear, analisar ou interpretar as "qualidades do conhecimento" que inspiram a ação humana durante a performance cultural. O autor trabalha com o conceito de Singer (1972) de "performance cultural": uma forma de expressão artística que obedece a uma programação prévia da comunidade, com local próprio para sua ocorrência, horário definido para início e fim das atividades, delimitação entre performers e público” (p.231).
}

narradores da associação. Justamente, porque a educanda-educadora-contadora de histórias Maria Lacerda se propôs a participar de um evento organizado pela pesquisadora educadora-contadora de histórias no teatro-escola Basileu França em novembro de 2015. A educanda-educadora-contadora de histórias contou uma história que foi vivenciada na infância. Apreendemos que "a narração da própria vida é o testemunho mais eloquente dos modos que a pessoa tem de lembrar. É a sua memória” (BOSI, 2004, p.68). A história contada foi:

\begin{abstract}
"Um homem morreu na região do nordeste, bem no interior. Não tinha esse negócio de caixão, era velado em cima de uma mesa ou um banco. Para enterrar o homem colocaram ele em um lençol - um homem seguro em um ponta e outro em outra ponta. Estão indo, indo de repente não ficam muito certo do caminho. E agora? Não lembro de ter visto córrego nenhum, disse um dos homens que estava carregando o morto. Aquela dúvida... De repente ouviram alguém dizer: ei o caminho é por lá, não é por aqui não. Eles levaram o maior susto e saiu correndo. Era o morto que levantou e apontou o caminho certo" (Diário de Campo, 2016).
\end{abstract}

Ao assumir a liberdade de contar, ao criticar a sociedade que silencia os idosos, a educanda-educadora- contadora de histórias Maria Lacerda dá vida e voz à história que estava guardada / escondida dentro de si. Sendo

${ }^{8} \mathrm{O}$ evento se intitulou: Vai...idade - além do tempo. O evento se realizou dentro da XIV Mostra de Teatro Desaguar, no Instituto Tecnológico do Estado de Goiás em Arte Basileu França . A educadora-educanda-contadora de histórias Joana Dark convidou instituições que trabalham em prol do idoso para participar. Esse evento foi possível, porque Joana Dark atua como professora do Grupo de Teatro Vai...idade, que é composto por pessoas acima de 50 anos. Nesse dia 150 idosos participaram com apresentações no palco do teatro-escola Basileu França 
assim, Maria Lacerda Educadora-educandacontadora de histórias dá voz a sim mesma, experiência o ato de expressar por meio da contação de história e liberta-se da opressão do silenciamento da sociedade, ou seja, "a ideia da liberdade só adquire plena significação quando comunga com a luta concreta dos homens por libertar-se” (WEFFORT apud FREIRE, 1999)

Com o desenvolvimento do círculo de cultura de contação de histórias, os educandos-educadores da Associação de Idosos foram percebendo que são livres para dizer e pronunciar sua palavra. Ao redescobrir essa liberdade, recriam histórias que estavam silenciadas pela opressão social em não poder ser. Contudo, muitas vezes "submetidos aos mitos da cultura dominante, entre eles o de sua "natural inferioridade", não percebem, quase sempre, a significação real de sua ação transformadora sobre o mundo" (FREIRE, 1981, p.41). A partir das reflexões, vivências e ressignificações das leituras de mundo, os educandos-educadores-contadores de histórias têm compreendido o potencial de sua ação transformadora no mundo por meio de suas experiências.

\section{Considerações finais}

O círculo de cultura de contação de histórias apresentou aos idosos da Associação a possibilidade de dizer criticamente seu mundo vivido. O mundo é algo próprio do ser humano e no percurso, no trilhar do caminho, toda a transformação advinda do trabalho do idoso e do dizer seu mundo é simplesmente silenciada. Por isso, o círculo de cultura de contação de histórias trabalhou para que os idosos pudessem transformar o mundo através de seu trabalho, "dizer" o mundo, expressá-lo e expressar-se são o próprio dos seres humanos. ”(FREIRE, 1981,p.20).
A ação reflexão de pronunciar, de dizer o mundo por meio da contação de histórias tem nos levado a perceber que no decorrer da vida dos idosos ocorre a negação da palavra. Por causa dessa negação "a palavra que, na situação concreta em que se encontram lhes está sendo negada. No fundo, negar a palavra implica em algo mais. Implica em negar o direito de "pronunciar o mundo" (FREIRE, 1981, p.13). Assim, ao ser negado o pronunciamento de sua palavra automaticamente os seus conhecimentos são silenciados.

Diante disso, a cada história contada no círculo de cultura procuramos problematizar o mundo, a sociedade de hoje. Justamente para que os idosos possam perceber que podem atuar no mundo, que são criadores e guardiões da cultura. Dessa forma, no decorrer de dois anos de envolvimento na Associação de Idosos entendemos que nos círculos de cultura de contação de histórias os idosos "vão organizando uma forma cada vez mais justa de pensar, através da problematização de seu mundo, da análise crítica de sua prática, irão podendo atuar cada vez mais seguramente no mundo". (FREIRE, 1981, p.17)

A partir da convivência no círculo de cultura de contação de histórias, os idosos têm percebido o valor de suas histórias. Essas histórias podem fazer parte do seu ato de contar, ao fazer a sua leitura de mudo reconhece: 0 estar no mundo e o poder dizer sua palavra. Esse ato de ação reflexão do próprio mundo é uma conquista. Assim "sua presença no mundo, pela assunção crítica desta presença, o que implica no reconhecimento de não apenas estarem no mundo, mas com o mundo" (FREIRE, 1981, p.17).

Dessa forma, os círculos de cultura de contação de histórias têm contribuído para que os participantes assumam, cada vez mais, o seu lugar e suas possibilidades no mundo e com o mundo. Isto é, “dizer a palavra, em um 
sentido verdadeiro, é o direito de expressar-se e expressar o mundo, de criar e recriar, de decidir, de optar. Como tal, não é o privilégio de uns poucos com que silenciam as maiorias”. (FREIRE, 1981, p.41).

Com o desenvolvimento do círculo de cultura de contação de histórias, os educandos-educadores da Associação de Idosos vão percebendo que são livres para dizer e pronunciar sua palavra. Ao redescobrir essa liberdade recriam histórias que estavam silenciadas pela opressão social em não poder ser. Contudo, muitas vezes "submetidos aos mitos da cultura dominante, entre eles o de sua "natural inferioridade", não percebem, quase sempre, a significação real de sua ação transformadora sobre o mundo” (Freire, 1981, p.41).

Os círculos de cultura de contação de histórias têm ressignificado as leituras de mundo. Refletindo junto com os educandos-educadores idosos sobre sua condição de "semeadores de palavras”, procurando emergir da cultura do silêncio (FREIRE, 1981, p.52). Ao emergir da cultura do silêncio os idosos recuperam o seu posto de criador e guardião da cultura, posto este que sempre foi seu.

Porém, esse posto é silenciado pela sociedade. No círculo de cultura de contação de histórias os idosos educandos-educadores-contadores de histórias semeiam suas palavras, suas experiências e reconhecem que são criadores e guardiões da cultura - emergindo da cultura do silêncio e mostrando a sociedade e aos outros idosos a sua vontade em ser mais.

\section{Referências}

BENJAMIN, W. O narrador: considerações sobre a obra de Nikolai Leskov. Magia e técnica, arte e política: ensaios sobre literatura e história da cultura. São Paulo: Brasiliense, 2012.
BOSI, E. Memória e sociedade: lembranças de velhos. 11. ed. São Paulo: Companhia das Letras, 2004.

CHAUÍ, M. Os trabalhos da memória. In: BOSI, E. Memória e sociedade: lembranças de velhos. São Paulo: Companhia das Letras, 2004.

FIORI, E. M. Aprender a dizer a sua palavra. In: FREIRE, P. Pedagogia do oprimido. Rio de Janeiro: Paz e Terra, 1987.

FREIRE, P. Educação como prática da liberdade. Rio de Janeiro: Paz e terra, 1999.

A importância do ato de ler: em três artigos que se completam. São Paulo: Autores associados: Cortez. 1989.

. Pedagogia do oprimido. São Paulo: Paz e Terra, 1987.

.Pedagogia da autonomia. Saberes necessários à prática educativa. São Paulo: Paz e terra, 1996.

.Ação cultural para a liberdade. $5^{\mathrm{a}}$ ed., Rio de Janeiro, Paz e Terra. 1981.

HARTMANN, L. Gesto, palavra e memória: performances narrativas de contadores de causos. Florianópolis: EDUFSC, 2011.

WEFFORT, F. C. Educação e política: reflexões sociológicas sobre uma pedagogia da liberdade. In: FREIRE, Paulo. Educação como prática da liberdade. Rio de Janeiro: Paz e Terra, 1967. 